\title{
Almond hulls in swine diet reduce body fat
}

\author{
Josep M. Homedes \\ Dan L. Brown \\ ㅁ Nancy L. Keim \\ Eugeni Roura \\ Nancy L. Keim
}

containing more than $9 \%$ ash are required to be labeled "almond hulls and dirt."

Almond hulls are in abundant supply in California. Unlike many horticultural by-products, almond hulls are dried in harvesting, which makes them attractive for livestock feed by reducing transportation costs and allowing for long-term storage.

The present study measured the exact digestible, metabolizable, and net energy content and the efficiency of energy utilization of almond hulls by growing swine. Values obtained would allow us to include almond hulls of similar chemical composition in balanced commercial swine diets.

\section{Background}

Twenty-two, 40- to 50-kg (90- to 110 pound), growing-finishing barrows, nine Duroc and thirteen crossbred (Hampshire $x$ Yorkshire), were fed two different diets for 35 days. The control (basal) diet was a typical corn/soybean-based diet (table 1). The alternative was a $85 \%$ basal diet plus $15 \%$ almond hulls.

At the trial's beginning, 17 animals were transported to the U.S. Department of Agriculture's Western Human Nutrition Research Center at the Presidio of San Francisco. There, they were scanned by total body electrical conductivity (TOBEC) to determine their exact body composition. Later the same day, they were placed in individual crates at the UC Davis Cole facility and fed ad libitum for an average of 35 days. At some time during the 35 days, each pig was moved to a metabolism

\begin{tabular}{|c|c|c|c|c|c|}
\hline \multicolumn{2}{|c|}{$\begin{array}{c}\text { TABLE 1. Feedstuffs composition of the basal } \\
\text { diet }\end{array}$} & \multicolumn{4}{|c|}{ TABLE 2. Average chemical composition of diets } \\
\hline Ingredient & $\%$ & \multirow{2}{*}{ Hulls } & \multirow{2}{*}{ Basal } & \multirow{2}{*}{$\begin{array}{l}\text { Basal+ } \\
\text { almond } \\
\text { hulls }\end{array}$} & \multirow{2}{*}{ Almond } \\
\hline Corn & 77.03 & & & & \\
\hline Soybean meal $47.5 \%$ protein & 19.75 & & \multicolumn{3}{|c|}{ 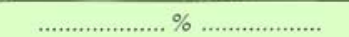 } \\
\hline Dicalcium phosphate & 1.45 & & & & \\
\hline Limestone & 1.10 & Dry matter & 88.4 & 88.8 & 90.9 \\
\hline Salt & 0.32 & Protein & 16.4 & 14.3 & 3.9 \\
\hline Vit-Mineral premix* & 0.30 & Ether extract & 3.6 & 3.4 & 2.3 \\
\hline L-Lysine $78.4 \%$ & 0.05 & NDF & 9.9 & 13.9 & 28.2 \\
\hline \multirow{4}{*}{\multicolumn{2}{|c|}{$\begin{array}{l}\text { 'Each kg of Vit-Mineral premix contains: vitamin } \mathrm{A} \text {, } \\
2.2 \mathrm{MIU} \text {; vitamin } \mathrm{D}_{3}, 0.88 \mathrm{MIU} \text {; vitamin } \mathrm{E}, 3.5 \mathrm{KIU} \text {; } \\
\text { menadione, } 0.5 \mathrm{gr} \text {; riboflavin, } 1.5 \mathrm{gr} \text {; pan acid, } 5.5 \mathrm{gr} \text {; } \\
\text { niacin, } 11.02 \mathrm{gr} \text {; choline, } 148 \mathrm{gr} \text {; vitamin } \mathrm{B}_{12}, 7.7 \mathrm{mg} \text {; } \\
\text { folic acid, } 0.02 \mathrm{gr} \text {; thiamine, } 0.47 \mathrm{gr} \text {; pyridoxine, } 0.44 \\
\text { gr; biotin, } 26.4 \mathrm{mg} \text {; Mn, } 13 \mathrm{gr} \text {; Fe, } 22 \mathrm{gr} \text {; }, 0.8 \mathrm{gr} \text {; } \mathrm{Cu} \text {, } \\
3.5 \text { gr: } \mathrm{Zn}, 33 \mathrm{gr} \text { Se, } 27 \text { ar; ethoxyquin, } 22 \mathrm{gr} \text {. }\end{array}$}} & $\begin{array}{l}\text { ADF } \\
\text { Cellulose }\end{array}$ & $\begin{array}{l}3.0 \\
2.9\end{array}$ & $\begin{array}{l}5.7 \\
4.5\end{array}$ & $\begin{array}{l}19.0 \\
13.3\end{array}$ \\
\hline & & Lignin & 0.7 & 1.6 & 6.3 \\
\hline & & Ash & \multicolumn{3}{|c|}{$\mathrm{kcal} / \mathrm{kg}$................ } \\
\hline & & Gross energy & 4,339 & 4,381 & 4,325 \\
\hline
\end{tabular}

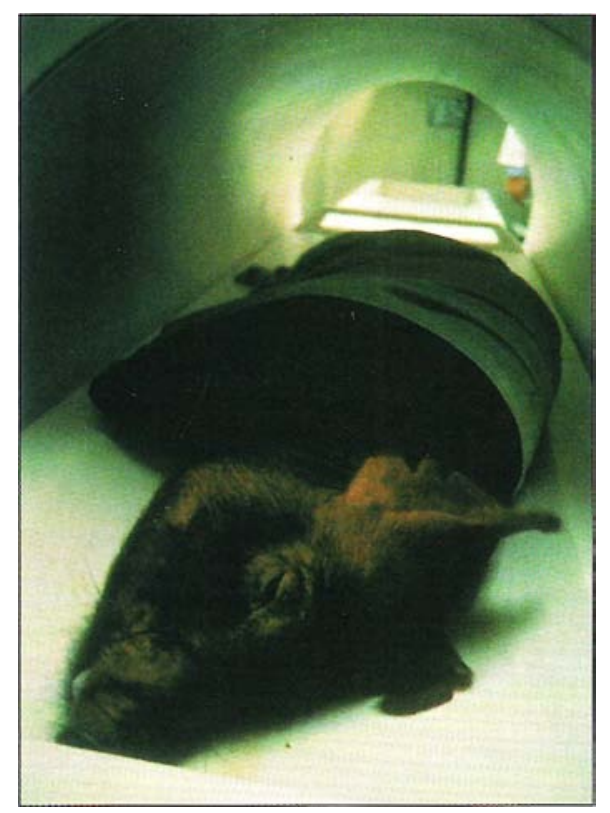

Duroc barrow is scanned for total body electrical conductivity (TOBEC).

crate for a 5-day collection of feces and urine. When the feeding trial ended, the pigs were scanned again by TOBEC to assess changes in body composition.

A second trial was conducted to determine digestible and metabolizable energy values. Four periods of total urine and feces collection from five litter mates provided the specimens needed for those determinations.

Proximate analysis and calorimetry was performed on feeds (table 2), feces and urine to obtain digestible and metabolizable energies (DE, ME).

Recent research shows that energy maintenance requirements are likely to be more closely related to body protein mass than to body weight. Therefore, fasting heat production (FHP) was estimated from lean tissue (obtained by TOBEC) as FHP (kcal/day) = 86 (lean mass in $\mathrm{kg}$ ) 0.84 .

Net energy (NE) was obtained from changes in body composition and FHP, divided by total dry matter intake during
Depending on the almond variety, chemical composition of hulls varies. Protein content reportedly ranges from 2.1 to $8.8 \%$, although little is believed to be available for maintenance or production. Crude fiber ranges from 10 to $24.9 \%$. Acid detergent fiber ranges from 20.6 to $35.2 \%$, neutral detergent fiber from 10 to $15 \%$, cellulose from 20.6 to $35.2 \%$, and crude lignin from 7.5 to $15.6 \%$. Ash content varies from 7.0 to $8.3 \%$ and can be higher, depending on the harvesting method used. Sugar content ranges from 18 to $30 \%$.

California requires almond hulls containing more than $15 \%$ crude fiber to be labeled "almond hulls and shells." However, in earlier research at UC Davis, acid detergent fiber was shown to be a better indicator of feed quality and digestibility, at least for ruminants. Also, shipments 


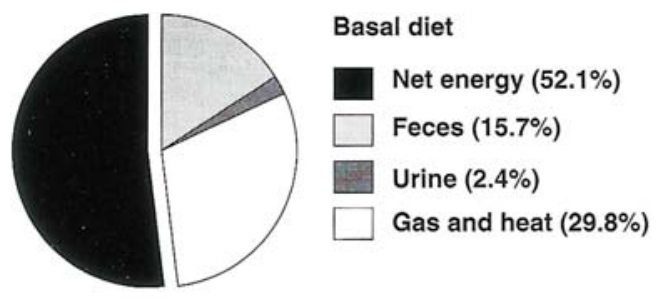

Fig. 1A. Basal diet energy utilization ( $\%$ of gross energy).

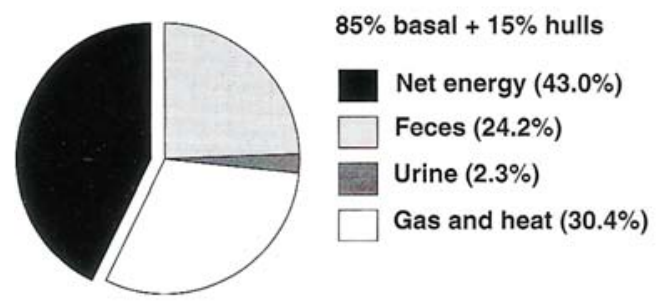

Fig. 1B. Fifteen percent almond hull diet energy utilization ( $\%$ of gross energy).

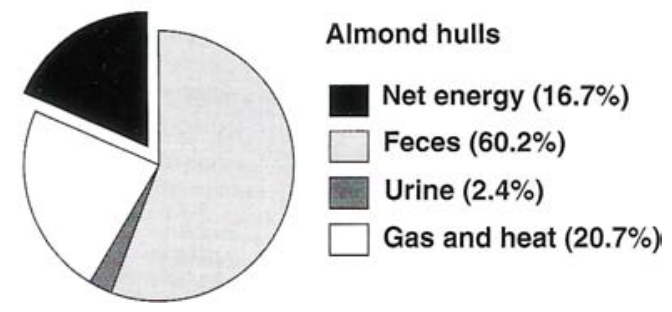

Fig. 1C. Almond hull energy utilization (\% of gross energy). the 35 days of feeding. All data were analyzed by SAS analysis of variance (ANOVA) procedure with diet, season and their interaction as sources of variation.

\section{Results}

In both groups, pigs had similar daily gain and final weight (table 3 ). However, feed efficiency ( $\mathrm{kg}$ feed per $\mathrm{kg}$ gain) was $5 \%$ less favorable for the $15 \%$ almond hulls diet. Pigs fed the $15 \%$ almond hulls diet ate $11 \%$ more than those fed the basal diet.

Treatment affected carcass quality substantially (table 4). Pigs fed $15 \%$ almond hulls had $16 \%$ less final fat than those fed the basal diet. The addition of almond hulls resulted in leaner carcasses, higher final protein percentages and a 10\% lower fat/protein gain ratio.

Although the net energy content of the $15 \%$ almond hulls diet (table 5) was low, pigs were able to increase their daily intake to get enough calories and to maintain a growth rate similar to the pigs on the control diet.

The almond hulls' low energy content can be explained by their low digestibility. The basal diet had a digestibility coefficient of $88 \%$. Adding $15 \%$ almond hulls to the diet reduced its digestibility by $10 \%$. Therefore, digestibility of almond hulls calculated by difference was only $44 \%$. The calculated gross energy loss to feces from almond hulls was much greater than that lost from the control diet (figures 1A, $1 \mathrm{~B}, 1 \mathrm{C})$. Losses in gas and urine, expressed

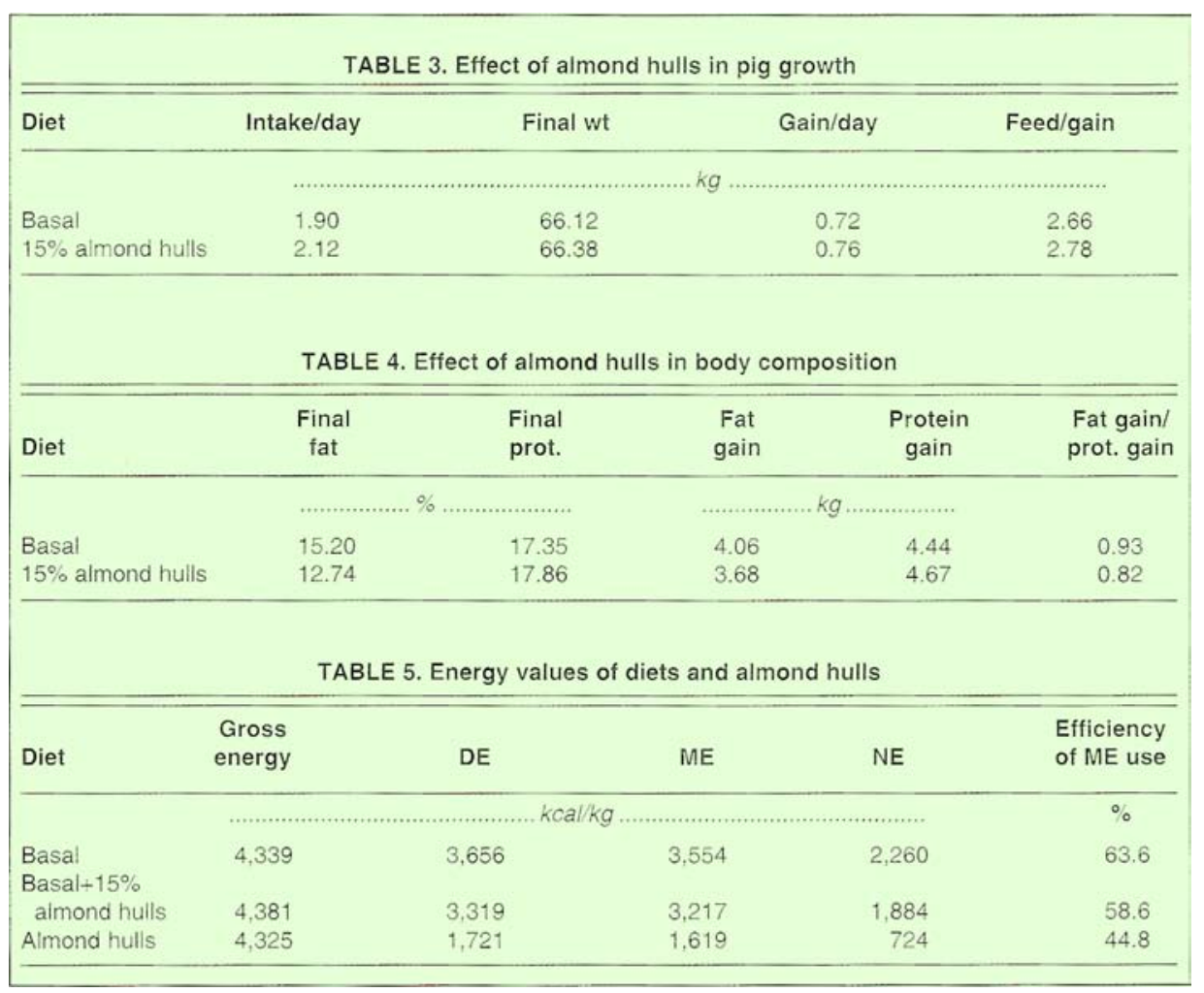

as a percentage of the gross energy, are similar for both diets. However, they represent a larger percentage of digestible energy for the almond hulls diet.

The resulting net energy (NE) usable for maintenance and growth was $63.6 \%$ of the metabolizable energy (ME) for the basal diet, and $44.8 \%$ for the almond hulls. This difference is probably due to the higher fiber content of the almond hulls, which causes a higher percentage of nutrients to be fermented in the hind gut. The volatile fatty acids (VFA) produced most likely have a lower metabolic efficiency than the glucose absorbed in the small intestine in normal diets.

A net energy system for swine diet evaluation would reduce the practical effects of variations in ME utilization, especially when fibrous feedstuffs are included in the diet in combination with high energy concentrates.

\section{Conclusions, recommendations}

The percentage of swine body fat was reduced by adding 15\% dietary almond hulls. This may result in improving carcass grade. Therefore, where maximum rates of gain are less important than carcass quality, it may be beneficial to include almond hulls in the diets of finishing pigs.

Because the net energy content is limited, almond hulls may have their greatest potential for use in gestation diets and for breeding stock, where energy restriction is often desirable. The almond hulls' high fiber content would keep the animals satisfied, yet avoid excessive fattening and constipation. The energy values of almond hulls reported here for growing and finishing swine probably indicate their value for mature pigs as well. To ensure accuracy of net energy determinations (the larger lower gut of mature swine may or may not permit more complete degradation of almond hulls), and to check for any negative effects on fetal development or fertility (almond hulls contain tannins and other secondary compounds), additional trials with gestating and breeding animals will be needed.

J. M. Homedes conducted these trials as part of his M.S. program in nutrition with the UC Davis Department of Animal Science; $E$. Roura assisted while preparing for his M.S. in nutrition with the UC Davis Department of Avian Science; N. L. Keim is Research Chemist at the USDA Western Human Nutrition Research Center, Presidio of San Francisco; and D. L. Brown is Associate Professor and Nutritionist, UC Davis Department of Animal Science.

The authors wish to express their appreciation to Patrick Mayclin, Scott Taylor, Lisa Holmes and Arthur Brito. 